\title{
The Role of advocacy within the mental health forensics services towards rehabilitation in the United Kingdom
}

\begin{abstract}
My role as a Mental Health Advocate involves empowering and enabling individuals within the Adult Forensic Services suffering with Mental Health Disorders to voice their needs through their journey towards rehabilitation abiding by the UK Mental Health Act 2007 Code of Practice, and respecting their Autonomy. The desire to write this mini journal came from my passion as a Psychotherapist being privileged to incorporate my skills and knowledge into the role of a Mental Health Advocate supporting them towards recovery and rehabilitation. The aim of this journal is to highlight the challenges and complexity of the role of a Mental Health Advocate and how I personally manage my work ethically as a professional within the Forensic Mental Health Services.
\end{abstract}

Volume 3 Issue 2 - 2016

\author{
Amina Begum \\ University of Warwick, UK
}

Correspondence: Amina Begum, University of Warwick, 123 Denville Crescent Bordesley Green, UK, Tel 44 7808666563, Email a.begum0I@hotmail.co.uk

Received:September 28, 2015 | Published: December 22, 2016

\section{Word definitions}

\section{Forensic mental health services}

Forensic Mental health Services work with people who have a mental illness and have been involved with the police, court or prison.

\section{Independent mental health advocate}

This service provides an Independent additional safeguard for patients who are subject to the Mental Health Act. Advocates are trained specifically to work within the framework of the Act to meet the needs of patients supporting them throughout their treatment by representing them and speaking on their behalf. Also providing information regarding their rights under the Act and participating in their care plan eg; attending Legal Tribunals, attending medical care plans/meetings, attending to patient needs and enquiries, Support with Finances and domestic issues etc...

\section{Autonomy}

Independence, Freedom to determine one's own actions, choice.

\section{Congruence}

This term describes the attitude of being real, genuine and real without the pretence of a professional façade.

\section{Empathy}

Empathic understanding is the ability to have a deep understanding of the individual's world 'as if' it were my own. To communicate this with sensitivity by being appropriately transparent focusing on their emotions, tone of voice, body language, feelings and meanings for the benefit of the individual's well-being through effective listening skills and communication skills, verbal and non-verbal.

\section{Unconditional positive regard}

This term refers to be in full acceptance of an individual and every facet they bring without any personal judgement. As a professional it is important for me to prize the individual as a human being and respect their Autonomy, their values and beliefs.

\section{Actualising tendency}

This term refers to being a fully functioning person who is in touch with and understands their reality, feelings, emotion's and places a deep trust in their own instincts and urges. This theory derives from the work of Carl Rogers (Person Centred Theory) who believed that all individuals have innate resources within them to be able to reach their full potential despite any hindrances or trauma they may have experienced. This process is called the 'Actualising Tendency'.

\section{Person centered theory}

Carl Rogers was the originator of this approach and theory. Rogers believed 'that the only expert on knowing what is going on for a person is the person themselves'. ${ }^{1}$ Roger's theory rests on the presence of the actualising tendency as discussed above. Rogers believed that 'This resource can be tapped into only if 'a definable climate of facilitative psychological attitudes can be provided' Rogers, 1986:197). ${ }^{1}$ In the Person Centred Approach these attitudes are necessary and sufficient for psychological growth and change to take place which are; Congruence, Empathy and Unconditional Positive Regard. As a Person Centred Psychotherapist (my study of background) from my professional conduct with clientele work, personal experiences, training and research I fully agree with Roger's theory and have spent many years understanding the importance of embodying these attitudes as this is significant and vital to psychological growth and development within the work I do with individuals experiencing 
psychological tensions and Mental Health Disorders. I will discuss this in more depth through my journal, how I manage my work ethically and how my theoretical approach as a Psychotherapist works in collaboration as a Mental Health Advocate for the benefit of this patient group.

\section{Mental health disorder}

According to the Mental health Act Code of Practice 2007 the term Mental Disorder is defined as " any disorder or disability of the mind"2 which falls under specific criteria of the Mental Health Act and the potential consequences of the individual's mental disorder.

\section{Mental health code of practice}

Legal Framework and guidance for clinicians to intervene where necessary to protect people with mental health disorders and to protect others who may be at risk (public). The Code of Practice also gives information and guidance in terms of hospitalization for patients and their relatives as well information regarding treatment for mental health disorders, consent, different sections of the Mental Health Act and the legal rights of patients detained under the Act.

\section{Methodology \& best practice towards working ethically with patients who suffer with mental health disorders}

As discussed earlier my background and approach as a professional Psychotherapist and Advocate is having a Person Centred Approach embodying the attitudes of Congruence, Empathy and Unconditional Positive Regard at all times. Working in one of UK'S leading Forensic Mental Health Secure Services where patients are detained under the Mental Health Act it's highly important for me as their Advocate to work professionally and ethically, not only do I endeavor to provide an excellent service to meet the requirements of the patients needs but also to abide by the Mental Health Act Code of Practice 2007. The role of an Advocate in my view is one of importance in the area of sufferers of Mental Health Disorders and the Service providers due to the distortions individuals may experience related to their illness eg; schizophrenia, Bi-polar, Paranoid Schizophrenia, Personality disorders, Manic Depression etc... where they may experience distortions, Paranoia, hearing voices etc... all of which are a hindrance and block to effective understanding/communication of their past criminal offence, present behaviour, voicing their needs and concerns, and managing a safer healthier lifestyle towards their road to rehabilitation back into the community.

In order for me to be able to communicate effectively with the patient's I am in contact with and to get an understanding of their needs it's vital for me to create a safe environment which provides the necessary and sufficient soil for psychological contact, growth, and to build a trusting relationship where in the Patient can convey his wishes and queries, feel heard and get a better understanding of his Mental Health Issues and reality. All this is vital towards the patient's recovery and treatment. By embodying an attitude of Congruence, Empathy and Unconditional Positive Regard I endeavor to create a safe environment; Being Congruent allows me to be real, genuine and authentic not only with my colleagues, clinical professionals but also with the patients for eg; if the patient makes a request which is not valid according to the Mental Health Act I can refer to the code of practice and convey the facts exploring other options which may meet the patients requirements as well as meet the criteria of the Mental Health
Act. This process helps to build trust with patients, communicate in an effective manner as their advocate maintaining boundaries and principles and working ethically; Mearns and Thorne state that "... congruence conveys the message that it is not only permissible but desirable to be oneself". ${ }^{3}$ The attitude of Congruence also allows me to challenge any clinical treatment plans on behalf of the patients at their request working in collaboration with the clinical team for the best interest of the patient and also abide by the Ethics of the Mental Health Code of Practice 2007. This helps further understanding for the patient leading to building better trust and relationships with the clinical team, and also allows the space to challenge any confusions/ thoughts on the patient's behalf due to their Mental Health Disorder, allowing the patient's to voice their needs and concerns via myself as their advocate or by themselves. Empathic understanding is 'the capacity to track and sense accurately the feelings and personal meanings'. ${ }^{3}$ Being empathic allows me to get a deep understanding of the patients concerns, needs and any difficulties or tensions they may be experiencing. It is only by being empathic that I can convey this for the patient, at their request. Having Unconditional Positive Regard allows me to have a non-judge mental attitude and prize the patient as a human being and respect their Autonomy. This helps build trust with my professional contact and 'he is also more likely to face himself honestly without the ever-present fear of rejection or condemnation's allowing room for exploration and discussions of difficulties or concerns he may be experiencing.

For me the role of an advocate helps to facilitate understanding and fills the gap of any communication breakdown or difficulties effectively with the professionals and clinicians involved within the treatment plan. This process allows not only better communication and understanding for the patients, helping them to build trust and be heard but also allows the professional clinicians to get a better understanding of the patients needs and treatment as I will evidence with the following example of patient contact; (Name has been anonymised to protect patient's identity). Patient $M$ suffers from paranoid schizophrenia and believed that the clinical teams were injecting him while he was sleeping. Patient $\mathrm{M}$ felt very frightened and disengaged from the clinical team by not attending his weekly care plan meetings and isolating himself to his bedroom. This has been going on for the last few weeks but Patient M did not disclose this issue to any of the clinical team members. This concern was bought to my attention by Patient M who approached me as I am 'Independent' and not employed by the Mental Health Services. Listening to his concerns I empathized and acknowledged his fear, this helped to build trust with Patient $\mathrm{M}$ and allowed him to understand that I am willing to listen and trying to understand what is going on for him. Being congruent I challenged his thought process of clinicians injecting him while he was asleep and if he had seen anyone leaving his room or noticed anything in his room? He replied 'no' this helped Patient $\mathrm{M}$ to think about the events and reflect on any information and facts. Without judging Patient $\mathrm{M}$ and being in acceptance of his reality I asked what action he would like to take ? I did this to prize his Autonomy and right of choice as his advocate and also abiding by the code of ethics and patients rights in the ${ }^{2}$ which states that "Everything possible should be done to overcome barriers to effective communication". ${ }^{2}$

Patient $\mathrm{M}$ conveyed that he would like me to speak to his clinician about this issue as he felt afraid of being judged and what they will think of him. With the patient's consent I contacted his clinician who arranged to meet the patient and discuss his concerns, fears and 
allegations. Patient $\mathrm{M}$ requested my presence for support during this meeting. The meeting allowed Patient $\mathrm{M}$ to voice his concerns and what was going on for him, he spoke for himself during the meeting as he said he felt confident that I was present as his advocate and felt supported. His clinical team were present and discussed the issues raised which allowed the team as well as Patient M to get a better understanding and insight into his mental health, struggles and tensions he has been experiencing. The process of the meeting not only allowed space and room for Patient M to speak and be heard building better communication and trust within his clinical team challenging his distortions, but also allowed Patient $\mathrm{M}$ to be part of his treatment plan and explore different ways towards recovery eg; medication, psychology groups etc... In order for me to work ethically and provide a service abiding by the Mental Health Code of Practice and abide by my role as an Independent Advocate for the Beneficence (in the best interest) of the patients I am in contact with without barriers or hindrance to my communication, supervision and being Phenomenological is a vital tool. As a professional the process of Phenomenology allows me to be authentic, congruent and nonjudgemental. The process of Phenomenology 'involves bracketing off the assumptions one holds about the phenomenon being invested, and striving to describe it in as comprehensive and sensitive manner as possible'. ${ }^{4}$ Any hindrances or judgements that may arise are bracketed off and discussed through confidential supervision with my manager allowing growth and development for me both professionally and personally. Learning and incorporating the philosophy of Phenomenology from the perspective of a Psychotherapist has helped me to be able to work ethically with this patient group as their Mental Health Advocate alleviating any personal judgments, and allowing the room for authenticity, empathy and acceptance which provides the sufficient soil for psychological growth towards the actualizing process for individuals on their road to recovery and rehabilitation.

\section{Acknowledgments}

None.

\section{Conflicts of interest}

None.

\section{References}

1. Haugh S, Paul S. The Therapeutic Relationship perspectives and themes PCCS Books Ltd., UK, 2008; pp. 1-280.

2. Code of Practice Mental Health Act 1983. Department of Health, TSO Information and Publishing Solutions, London, 2007; pp. 1-457.

3. Mearns D, Thorne B, McLeod J. Person Centred Counselling in Action, Sage Publications Ltd., London, 2013; pp. 1-240.

4. McLeod J. An Introduction to Counselling. Open University Press, USA, 1998; pp. 1-446. 